\title{
SIGNIFICACIONES SOBRE LA PAZ, EL PROCESO DE INTERNALIZACIÓN DEL APRENDIZAJE Y LAS COMPETENCIAS SOCIOAFECTIVAS, EN LOS NICHOS DE INTERACCIÓN PEDAGÓGICA DE LA ESCUELA EN
} EL PREESCOLAR

\section{MEANINGS ABOUT PEACE, THE PROCESS OF INTERNALIZATION OF LEARNING AND SOCIO- AFFECTIVE COMPETENCES, IN THE NICHES OF PEDAGOGICAL INTERACTION IN THE PRESCHOOL SCHOOL.}

Emperatriz Perdomo Cruz ${ }^{1}$ Universidad Americana de Europa en Cancún, México

Leidy Carolina Cuervo² Universidad Surcolombiana en Neiva, Colombia, Universidad del Tolima

Eduardo Plazas Motta ${ }^{3}$ Universidad Surcolombian

$1 \quad$ Licenciada en Pedagogía Infantil y Magíster en Educación, de la Universidad Surcolombiana de Neiva, en Neiva-HuilaColombia. Doctora en Educación de la Universidad Americana de Europa en Cancún-México, Investigadora Grupo Paz desde la Paz de la Universidad Surcolombiana de Neiva, Docente Universitaria y Docente de Preescolar en Neiva-Huila-Colombia. Correo electrónico: empera1199@yahoo.es. https://orcid.org/0000-0002-3336-472X

2 Licenciada en Pedagogía Infantil, Especialista en Integración Educativa y Magister en Educación, de la Universidad Surcolombiana en Neiva-Colombia. Doctora en Educación de la Universidad Americana de Europa en Cancún-México. Coordinadora Grupo Paz desde la Paz de la Universidad Surcolombiana de Neiva y Docente Universitaria en Neiva-Huila-Colombia y universidad del Tolima. Correo electrónico: caritocuervo2011@hotmail.com. https://orcid.org/0000-0002-6927-0776

3 *Licenciado en Administración Educativa y Especialista en Pedagogía, de la Universidad Surcolombiana en NeivaColombia, Especialista en Docencia Universitaria de la Universidad Cooperativa de Colombia en Neiva- Colombia, Magister en Educación de la Universidad del Valle en Cali-Colombia, Doctor en Educación de la Universidad DEUSTO en Bilbao- España y Docente Universitario.eduardo.plazasm@usco.edu.co https://orcid.org/0000-0002-4471-4481 


\section{RESUMEN}

La cultura de la violencia se ha internalizado en las formas de pensar, de hablar, en las actitudes y comportamientos en la Escuela, la violencia es ejercida hacia los niños, las niñas, por lo que se hace necesario promover la paz estrategia fundamental. La Paz interior es el fundamento de este estudio, es un estado de serenidad y armonía perdurable e inalterable que trasforma a la persona desde su interior, se sustenta en las virtudes. Y la Paz Imperfecta que reconoce el conflicto como elemento constitutivo de la vida humana y potenciador de la misma, motor del desarrollo, son los conflictos los que desinstalan, generan incomodidad y conducen a buscar formas de vida más conciliadoras e incluyentes. (Muñoz, 1998, p. 46). "La internalización hace referencia a un proceso de autoconstrucción y reconstrucción psíquica, a una serie de transformaciones progresivas internas, originadas en operaciones o actividades de orden externo, mediadas por signos y herramientas socialmente construidas" (Vigotsky, 1978, citado en Tortoza et al, 2012). Las competencias socioafectivas, las competencias son concebidas entonces como el conjunto de "recursos de funcionamiento cognitivo" con que los niños se enfrentan y responden a las demandas crecientes de un entorno que se considera variable durante el largo período de la infancia. (MEN, 2010, p. 6). A demás se elaboró la discusión de estos resultados contrastándolos con el referente teórico y conceptual del estudio, la Tesis de la Paz interior y la Paz Imperfecta.

\section{PALABRAS CLAVE:}

paz, internalización, competencias socioafectivas, conflicto y violencia

\section{ABSTRACT}

The culture of violence has been internalized in the ways of thinking, speaking, attitudes and behaviors at school, violence is exercised towards children, so it is necessary to promote peace as a fundamental strategy. Inner Peace is the foundation of this study, it is a state of serenity and lasting and unalterable harmony that transforms the person from within, it is based on virtues. And the Imperfect Peace that recognizes conflict as a constitutive element of human life and an enhancer of it, the engine of development, it is the conflicts that uninstall, generate discomfort and lead to seek more conciliatory and inclusive ways of life. (Muñoz, 1998, p. 46). "Internalization refers to a process of self-construction and psychic reconstruction, to a series of internal progressive transformations, originated in operations or activities of external order, mediated by socially constructed signs and tools" (Vigotsky, 1978, cited in Tortoza et al, 2012). Socio-affective competencies, competencies are then conceived as the set of "cognitive functioning resources" with which children face and respond to the growing demands of an environment that is considered variable during the long period of childhood. (MEN, 2010, p. 6). In addition, a discussion of these results was elaborated contrasting them with the theoretical and conceptual reference of the study, the Thesis of Inner Peace and Imperfect Peace.

\section{KEY WORDS:}

peace, internalization, socio-affective competences, conflict and violence.

\section{CONCIBIENDO LAS SIGNIFICACIONES SOBRE LA PAZ, EL PROCESO DE INTERNALIZACIÓN DEL APRENDIZAJE Y LAS COMPETENCIAS SOCIOAFECTIVAS, EN LOS NICHOS DE INTERACCIÓN PEDAGÓGICA DE LA ESCUELA EN EL PREESCOLAR}

La deshumanización, los continuos conflictos que han desencadenado en violentas guerras a nivel mundial, nacional y local, por luchas de poderes e ideologías erróneas de 
clase, raza, género, cultura, religión, política, etc., han desencadenado consecuencias funestas en las formas de relaciones, que se suscitan en los diferentes contextos de interacción del ser humano. La cultura de la violencia se ha internalizado en las formas de pensar, de hablar, en las actitudes y comportamientos de las personas, estas actitudes y comportamientos se han normalizado tanto en el diario vivir que se ha vuelto una problemática generacional, la violencia es ejercida de los adultos hacia los niños, las niñas o hacia las personas más débiles; de esta forma, cuando el niño va creciendo y llega a la adultez replica esta violencia hacia sus semejantes, dado que es la única forma que conoce para afrontar los conflictos de la cotidianidad.

La Paz es una utopía de todos y cada uno de los seres humanos, desde hace muchos años se han realizado grandes esfuerzos desde todas las disciplinas para lograrla, antes de la Segunda Guerra Mundial surgió una propuesta desde la teoría crítica, debido a la desigualdad social que existía, como crítica a la razón instrumental, principalmente como una opción de cambio en la sociedad; después de la guerra continuaron con este trabajo denominándolo la escuela de Frankfurt. Luego algunos teóricos consideraron que esta teoría crítica se podía llevar a la educación como una pedagogía crítica, que empezó a proporcionar una teoría radical y un análisis de la educación diferente, aún los teóricos críticos están unidos por sus objetivos: habilitar a los desposeídos y trasformar las desigualdades e injusticias sociales (McLaren, p.255 y 266,1998$)$.

Sus principios fundamentales se identifican con la sensibilidad del símbolo hebreo tikkun, que significa "curar, reparar y trasformar al mundo," proporciona dirección histórica, cultural, política y ética para los involucrados en educación; que aún se atreven a tener esperanza. Comprometida con el lado de los oprimidos, es revolucionaria, dado que la historia está fundamentalmente abierta al cambio, la liberación es una meta autentica y puede alumbrar a un mundo por completo diferente. Se analiza la escuela de una doble forma como mecanismos de clasificación y como agencias para dar poder social e individual, en la cultura para abolir la desigualdad, la fragmentación de las relaciones sociales democráticas. (McLaren, 1998, p. 25).La preocupación por la dimensión moral de la educación, ha llevado a los académicos críticos, a emprender una reconstrucción socialmente crítica de lo que significa ser escolarizado. Destacan que cualquier práctica pedagógica genuina, exige un compromiso con la trasformación social, en solidaridad con los grupos subordinados y marginados, una opción preferencial por el pobre y por la eliminación de las condiciones que consienten el sufrimiento humano (McLaren, 1998, p. 258).

Desde la anterior perspectiva, hace ya un tiempo considerable que la educación ha tenido que asumir la formación integral de los niños y las niñas, además, de impartir lo académico, es decir, los conocimientos fundamentales de las diferentes asignaturas o dimensiones, ha asumido la formación de lo personal en la enseñanza de los valores, de esta forma contrarrestar la cultura de antivalores, que genera violencia en los estudiantes. Prevenir la violencia y promover los valores de la Paz desde los contextos de interacción de la escuela, para trasformar las formas de las relaciones sociales que la rodean, con el propósito de que los cambios se susciten desde dentro de la Escuela hacia las comunidades en las que habitan los niños y las niñas.

La escuela se ha encargado de formar en las competencias socioafectivas desde los valores en los niños y las niñas, pero solo los trabajan como conocimientos del currículo, mas no de forma práctica para lograr trasformar la vida, tanto de los estudiantes como de sus 
familias y sus comunidades, las competencias socioafectivas entrañan las virtudes y los valores que son fundamentales, dado que promueven las interacciones para una sana convivencia en la escuela, de esta forma internalizar la Paz, esta se logra solo si se internalizan las virtudes y los valores en los comportamientos y actitudes en los contextos de interacción pedagógicos de la escuela.

En esta parte del estudio sobre la internalización de las virtudes y valores de la Paz mediante las competencias socioafectivas en los niños y las niñas del nivel preescolar, se estableció como segundo propósito esencial determinar la pertinencia de las competencias socioafectivas como mediadoras de la internalización de la Paz desde las interacciones pedagógicas de la escuela. En coherencia con las etapas y características de desarrollo y aprendizaje de los niños y las niñas del nivel preescolar, se observó sistemática y directamente la práctica pedagógica de los agentes educativos en los espacios y ambientes que constituyeron el referente empírico y del análisis de los principios teleológicos de la escuela confrontándolos con los fundamentos teóricos y conceptuales del estudio.

Se presentaron de forma puntual los resultados arrojados desde el trabajo empírico, es decir, derivado de la aplicación de la batería de instrumentos (cuestionario a docentes, entrevista a directivos docentes y registro de observación a los niños y las niñas del nivel preescolar) se efectuó el análisis de cada una de las fuentes consultadas, que garantizó un procedimiento general de la problemática en relación directa con el sustento teórico y conceptual; los resultados aquí plasmados se elaboraron por temas destacando la tendencia dentro de estas, tanto entre docentes, directivos docentes y estudiantes, las temáticas aquí abordadas fueron $\mathrm{Paz}$, internalización $\mathrm{y}$ competencias socioafectivas.
Además, se elaboró la discusión de estos resultados contrastándolos con el referente teórico y conceptual del estudio, la Tesis de la Paz interior que es el principal fundamento de este estudio, es un estado de serenidad y armonía perdurable $e$ inalterable que trasforma a la persona desde su interior, que se manifiesta hacia sus semejantes por medio de comportamientos y actitudes que construyen constantemente la Paz en sus interacciones, se sustenta en las virtudes de: el dominio propio, la bondad, la justicia, la esperanza, el afecto y la alegría.

Y la Paz, vista desde el paradigma de la Paz imperfecta que reconoce las debilidades como las fortalezas humanas, es imperfecta porque resulta de una realidad en la que conviven las regulaciones de conflicto pacíficas con las violentas, y porque lejos de una noción utópica no se busca llegar a la perfección sino convivir con la propia imperfección de nuestra naturaleza como seres humanos. Es una Paz que se construye en la cotidianidad y con el concurso de los otros. Una Paz que reconoce el conflicto como elemento constitutivo de la vida humana y potenciador de la misma, motor del desarrollo, son los conflictos los que desinstalan, generan incomodidad y conducen a buscar formas de vida más conciliadoras e incluyentes. (Muñoz, 1998, p. 46)

"La internalización hace referencia a un proceso de autoconstrucción y reconstrucción psíquica, a una serie de transformaciones progresivas internas, originadas en operaciones o actividades de orden externo, mediadas por signos y herramientas socialmente construidas" (Vigotsky, 1978, citado en Tortoza et al, 2012). Las competencias socioafectivas, las competencias son concebidas entonces como el conjunto de "recursos de funcionamiento cognitivo" con que los niños se enfrentan y responden a las demandas crecientes de un entorno que se considera variable durante el largo período de la 
infancia. (MEN, 2010, p. 6). "Las interacciones, comprenden las relaciones recíprocas o formas de actividad conjunta que establecen los niños y las niñas consigo mismos, con los demás y con los entornos naturales, físicos, sociales y culturales en los que ocurre su desarrollo (Bases curriculares," p. 33, 2017 et al, MEN, 2014a). Son las habilidades interpersonales e intrapersonales que adquieren los seres humanos en sus contextos de interacción, se relacionan directamente con las actitudes y actuaciones que demuestran desde los valores y las virtudes como el dominio propio, la bondad, la justicia, la esperanza, el afecto y la alegría.

\section{PREEMINENCIA LAS SIGNIFICACIONES SOBRE LA PAZ, EL PROCESO DE INTERNALIZACIÓN DEL APRENDIZAJE Y LAS COMPETENCIAS SOCIOAFECTIVAS, EN LOS NICHOS DE INTERACCIÓN PEDAGÓGICA DE LA ESCUELA EN EL PREESCOLAR}

Actualmente a nivel mundial, desde la educación se está implementando la Paz como parte del currículo en los diferentes niveles educativos, la UNESCO (2000) ha creado una red de escuelas para la Paz, cuyo objetivo primordial es brindar una educación de calidad fundamentada en la Paz. La Asamblea General de las Naciones Unidas (1979-1980), creó una Universidad para la Paz, como instituto internacional especializado de educación de posgrados, cuyo propósito principal es realizar estudios relacionados con la Paz. A nivel nacional y local, desde el Ministerio de Educación Nacional, se ha planteado como política educativa implementar la Cátedra de la Paz, desde la educación preescolar hasta la universitaria, que tiene como propósito esencial crear y consolidar un espacio para el aprendizaje, la reflexión y el diálogo sobre la cultura de la Paz, donde todas las instituciones educativas de carácter público y privado deben incluirla en sus currículos de forma obligatoria, pero es de acotar que muy pocas a nivel de educación básica lo han realizado, solo a nivel universitario lo han hecho.

La internalización, fundamentada en las teorías de aprendizaje social que afirman que si bien es cierto, el ser humano nace con una predisposición genética para aprender con unas estructuras mentales y físicas, que el aprendizaje no es innato sino que es el resultado de la internalización de las interacciones sociales de los niños y las niñas con los adultos y con sus pares. Entonces, el aprendizaje en los niños y las niñas primeramente se suscita de forma social, ellos internalizan todos lo que aprenden por imitación de los modelos con los que interactúan, por lo que desde edades muy cortas han internalizado la violencia, dado que conviven con adultos en contextos que diariamente se suscitan diversas manifestaciones de esta; cuando entran a la escuela replican estos comportamientos con sus pares.

El desarrollo socioafectivo del ser humano inicialmente estaba a cargo de la familia, principalmente bajo la responsabilidad de la madre, quien debía encargarse de la crianza de los niños y las niñas, pero debido a las nuevas exigencias de la sociedad posmoderna el concepto y tipos de familia han cambiado, las madres salen a trabajar por lo que las niñas y los niños quedan a cargo de miembros de su familia o de particulares, lo que ha generado que los valores hayan dejado de tener importancia en su crianza, acarreando una problemática social donde las infancias y juventudes muestran en sus comportamientos y actitudes los antivalores aprendidos. 
PROPÓSITOS DE LAS SIGNIFICACIONES SOBRE LA PAZ, EL PROCESO DE INTERNALIZACIÓN DEL APRENDIZAJE Y LAS COMPETENCIAS SOCIOAFECTIVAS, EN LOS NICHOS DE INTERACCIÓN PEDAGÓGICA DE LA ESCUELA EN EL PREESCOLAR

\section{Objetivo General.}

- Determinar la pertinencia de las competencias socioafectivas como mediadoras de la internalización de la Paz desde las interacciones pedagógicas de la escuela en coherencia con las etapas y características de desarrollo y aprendizaje de los niños y las niñas del nivel preescolar de la Institución Educativa Enrique Olaya Herrera Sede Central y Camelias, en la Comuna Diez de la ciudad de Neiva

\section{Objetivos Específicos.}

-Identificar las competencias socioafectivas para internalizar la paz desde las interacciones pedagógicas de la escuela en coherencia con las etapas y características de desarrollo y aprendizaje de los niños y las niñas del nivel preescolar de la Institución Educativa Enrique Olaya Herrera Sede Central y Camelias, en la Comuna Diez de la ciudad de Neiva.

- Caracterizar las significaciones de las competencias socioafectivos para internalizar la paz desde las interacciones pedagógicas de la escuela en coherencia con las etapas y características de desarrollo y aprendizaje de los niños y las niñas del nivel preescolar de la Institución Educativa Enrique Olaya Herrera Sede Central y Camelias, en la Comuna Diez de la ciudad de Neiva.

- Contrastar las significaciones de los agentes educativos y la implementación de las competencias socioafectivos para internalizar la paz, en las interacciones pedagógicas de la Escuela de acuerdo con las etapas y características de desarrollo y aprendizaje de los niños y las niñas del nivel preescolar, de la Institución Educativa Enrique Olaya Herrera Sede Central y Camelias, en la Comuna Diez de la ciudad de Neiva.

\section{EL FARO QUE PERMITE CONCEBIR LAS SIGNIFICACIONES SOBRE LA PAZ, EL PROCESO DE INTERNALIZACIÓN DEL APRENDIZAJE Y LAS COMPETENCIAS SOCIOAFECTIVAS}

\section{Conceptos.}

Estos conceptos permitieron abordar el estudio de la internalización de la Paz, en los contextos pedagógicos de interacción. Concepto de Paz Interior es el fundamento de este estudio, es un estado de serenidad y armonía perdurable $\mathrm{e}$ inalterable que trasforma a la persona desde su interior, se manifiesta hacia sus semejantes por medio de comportamientos y actitudes que construyen constantemente la paz en sus interacciones, se sustenta en las virtudes de: el dominio propio, la bondad, la justicia, la esperanza, el afecto y la alegría. Concepto de Paz Imperfecta que reconoce el conflicto como elemento constitutivo de la vida humana y potenciador de la misma, motor del desarrollo, son los conflictos los que desinstalan, generan incomodidad y conducen a buscar formas de vida más conciliadoras e incluyentes. (Muñoz, 1998, p. 46). Concepto de "Internalización hace referencia a un proceso de autoconstrucción y reconstrucción psíquica, a una serie de transformaciones progresivas internas, originadas en operaciones o actividades de orden externo, mediadas por signos y herramientas socialmente construidas" (Vigotsky, 1978, citado en Tortoza et al, 2012). Concepto de Competencias socioafectivas, las competencias son concebidas entonces como el conjunto de "recursos de funcionamiento cognitivo" con que los niños se enfrentan y responden a las demandas crecientes de un entorno que se considera variable durante el largo período de la infancia. (MEN, 2010, p. 6). 


\section{Variables.}

Fueron de carácter cualitativo, dado que la particularidad que midieron de la unidad de análisis o una cualidad, cada una de ellas están relacionadas directamente con el referente empírico y conceptual de la investigación y permitió leer la realidad estudiada acerca de la internalización de las virtudes de la paz mediada por la competencias socioafectivas. Las variables que se tuvieron en cuenta para el desarrollo de esta investigación, fueron definidas conceptualmente y están directamente coherentes con las que sustentan el referente teórico, conceptual y empírico de la misma. Variables: paz, internalizacion y competencias socioafectivos. Hernández Sampieri, Fernández Collado \& Baptista Lucio (2010).

\section{Población y Muestra.}

Dentro de la población de agentes con los que se ejecutó la investigación de la Institución Educativa Enrique Olaya Herrera se considera. Ludewig (1998). La población. Estuvo constituida por 4.555 agentes, que pertenecen a la institución educativa Enrique Olaya Herrera del sector público de la zona urbana de la ciudad de Neiva, segregados en directivos docentes, docentes, estudiantes y los padres de familia de los estudiantes. García Muñoz (2005). La muestra. Fue intencional, el $100 \%$ de los directivos docentes, el $100 \%$ de los docentes del nivel preescolar, el $100 \%$ de los estudiantes del nivel preescolar, y aproximadamente el $45 \%$ de los padres de familia de los estudiantes del nivel preescolar y estuvo constituida por 346 sujetos.

\section{Instrumentos de recolección de la información.}

Para efecto de la recolección de los datos, se elaboraron cuestionarios, entrevistas a profundidad y registros de observación, para dar cumplimiento a los objetivos propuestos, sobre el estudio de la internalización de las virtudes de la paz mediadas por las competencias socioafectivas, para la prevención de la violencia. Fàbregues, Meneses, Rodríguez, Gómez \& Paré (2016). El cuestionario Como elemento esencial, se consideró pertinente conocer la opinión de los docentes y los padres de familia, frente al desarrollo, estructuración e internalizacion la paz mediada por las competencias socioafectivas en los niños y niñas en el nivel de preescolar. Se realizó el diligenciamiento de los cuestionarios por parte de los siete (7) docentes de preescolar. El otro cuestionario se aplicó a setenta y siete (77) padres de familia. Hernández, Fernández \& Baptista (2010), citado por Brace (2008). La entrevista. Se realizaron a cinco (5) directivos docentes, (1) rectora, (3) coordinadores y (1) orientadora escolar. Se consideró como un recurso importante dado que se pretendió conocer las opiniones y concepciones acerca de la importancia de las competencias socioafectivas como mediadoras para la internalización de la paz, y opiniones acerca de la normatividad del (MEN).Hernández et al (2010). El registro de observación. Se aplicó veinte y cuatro (24) veces en total de las veinte y ocho (28) veces previstas, cuatro (4) por aula, a 143 niños y niñas de los 163 previstos en total, ubicados en seis (6) aulas. Solo una docente no permitió que se aplicara registro de observación en su aula. Hernández et al (2010).

\section{PROCESAMIENTO DE LA INFORMACIÓN DESDE LOS IMAGINARIOS $Y$ COMPORTAMIENTOS DE LOS AGENTES EDUCATIVOS CONCERNIENTES A LA PAZ, INTERNALIZACIÓN DEL PROCESO DE APRENDIZAJE Y COMPETENCIAS SOCIOAFECTIVAS.}

El procesamiento de la información de las preguntas objeto de análisis, que correspondían a cada una de las variables cualitativas mediante el programa NVIVO V. 12.0. Se crearon unos Nodos o variables de análisis de los conceptos que los docentes, padres de familia y directivos 
docentes respondieron en cada pregunta, los cuales fueron organizados a través de la técnica de Codificación Abierta; que es un proceso analítico por medio del cual se identifican los conceptos y se descubren en los datos sus propiedades y dimensiones. Codificación abierta: el proceso analítico por medio del cual se identifican los conceptos y se descubren en los datos sus propiedades y dimensiones.

Fenómenos: ideas centrales en los datos, representadas como conceptos.

Conceptos: basamentos fundamentales de la teoría.

Categorías: conceptos que representan fenómenos.

Propiedades: características de una categoría, cuya delineación la define y le da significado.

Dimensiones: escala en la cual varían las propiedades generales de una categoría, y que le da especificaciones a la categoría y variaciones a la teoría.

Subcategorías: conceptos que pertenecen a una categoría, que le dan claridad adicional y especificidad. Strauss \& Corbin (2002).

Este procedimiento se estructuro tanto en las respuestas del cuestionario de docentes y padres de familia y a la entrevista de directivos docentes. A continuación, se detalla la organización que se estructuro en el programa NVIVO. Por cada Nodo se desarrollaron unos SubNodos, para organizar el análisis del contenido de los conceptos. "Nodos o categorías de análisis, y codificación de los documentos. Como dijimos, los nodos son nuestras categorías de análisis. Podemos crearlos mediante dos maneras: a) los hemos acordado previamente, ya sea desde el marco teórico, equipo de investigación, etc., b) los podemos ir creando conforme vamos leyendo los relatos, entrevistas, grupos, o textos que deseemos analizar. Ambos procedimientos también se pueden realizar en el programa." Meneses Falcón (2019).

Mediante análisis estadístico, los datos cuantitativos se consolidaron a través de una matriz organizada en Microsoft office Excel, paquete de versión 2010. Los datos de las respuestas de las preguntas sociodemográficas y de los registros de observación, fueron analizaos estadísticamente, utilizando el software SPSS V 12.0. Se exploraron y depuraron para contrastar la normalidad de los datos mediante las pruebas de bondad Kolomogorv-Smirnov, con factor de corrección de significación Lilliefors para ver si cumplían las distribuciones normales. Romero-Saldaña (2016) Se aplicó la estadística descriptiva el análisis con frecuencias relativas y absolutas, se crearon variables dicotómicas que representaron los valores límites de cada variable, previamente determinados de acuerdo con los valores normales de la población, en las respuestas delas preguntas de las variables sociodemográficas, de igual forma se hizo el procesamientos de la información con las respuestas de los ítems de los registros de observación. Castañeda, Cabrera, \& Navarro (2010).

\section{RESULTADOS Y DISCUSIÓN SOBRE LAS SIGNIFICACIONES DE LA PAZ, LA INTERNALIZACIÓN DEL PROCESO DE APRENDIZAJE Y LAS COMPETENCIAS SOCIOAFECTIVAS, DESDE LA LECTURA DE LOS NICHOS DE INTERACCIÓN PEDAGÓGICA DE LA ESCUELA EN EL PREESCOLAR}

En este aparte se muestran la discusión de los resultados del estudio, en contrastación con la fundamentación teórica y conceptual, que orientó el marco del estudio acerca de la internalización de las virtudes y valores de la paz mediante las competencias socioafectivas. 


\section{CONCEPTUALIZACIONES SOBRE LA PAZ DE LOS AGENTES EDUCATIVOS.}

*Para algunos docentes la Paz es imperfecta, para otra positiva donde hay armonía y otro interior que fluye desde el espíritu y Paz negativa como ausencia de problemas, conflictos y violencia. Reconociendo la Paz como un derecho de cada ser humano y como un ideal que se puede construir desde la singularidad de la persona como la Paz interior. Además, relacionan la Paz con los valores como respeto, tolerancia, justicia y equidad, como un estado en el que hay seguridad, igualdad, equidad, en donde no hay guerra ni conflictos. Paz imperfecta. (López, 2001, p. 38). La Paz positiva (Muñoz, 2001, p.7). La Paz interior. La Paz negativa. (Muñoz, 2001, p. 6).

*Todos los docentes estuvieron de acuerdo en que la Paz sí es una problemática que concierne a la educación infantil, dado que los niños y las niñas están en distintos ambientes en los que pueden experimentar el conflicto por parte de los adultos de la familia y el barrio, que para ello es necesario que desde temprana edad que se les enseñe a generar procesos de autocontrol y resolución de conflictos a través del diálogo y acuerdos. Brindarles ambientes desde las competencias socioafectivas para promover su desarrollo armónico e integral. La escuela tiene mucho que hacer. (Zurbano, 2001a, p. 11).

*Para los docentes la Paz se debe abordar desde la primera infancia, fomentando una cultura de Paz, de esta manera formar adultos estables en un futuro. A través de ambientes saludables, acogedores y agradables, fundamentando los valores lo cual podría contribuir desde lo afectivo, para el afianzamiento del autoconcepto, autoimagen y autoestima elementos necesarios para una nueva sociedad. Educar para la convivencia pacífica en Educación Infantil (Zurbano, 2001a, p.11).
*Para los docentes la Ley 1620 del 2013 constituye una política en las Instituciones Educativas, que fortalece el desarrollo socioafectivo en los estudiantes, para fundamentar la educación para la Paz, promover la convivencia, resolver conflictos y prevenir y mitigar las violencias, que se maneja por medio del manual de convivencia. (Artículo 4, enciso 3, Ley 1620 de 2013).

*Para los docentes la cátedra de la Paz favorece el fomento una cultura de sana convivencia, que promueve ambientes pacíficos en las aulas de las instituciones educativas, para que los jóvenes se alejen de la violencia de las calles. Que es importante la educación para la Paz, es otra herramienta que pretende abordad la Paz desde lo curricular en la escuela y empoderar a la toda comunidad en la Paz. La Cátedra de la Paz tendrá como objetivo crear y consolidar un espacio para el aprendizaje, la reflexión y el diálogo sobre la cultura de la Paz y el desarrollo sostenible que contribuya al bienestar general y el mejoramiento de la calidad de vida de la población. (Artículo 1, enciso 3 y Articulo 3, Ley 1732 de 2014).

*Los directivos de la Institución definen la Paz como interior, porque debe comenzar por el interior de los corazones y viene desde el interior de los hogares. Es positiva donde hay un estado de tranquilidad absoluta, donde todo es bueno, confortable, agradable, es alcanzar un estado de total de armonía y equilibrio entre el corazón y la mente de todo individuo, que es positiva a nivel individual y social. Donde no hay preocupación, en la que hay ausencia de conflictos, es lo que todos desean y quieren vivir, es todo lo contrario a la agresividad y al odio; que es una Paz imperfecta, no está bien estructurada, no está bien definida. La Paz positiva (Muñoz, 2001, p.7). La Paz negativa" (Muñoz, 2001, p. 6).

*Para los directivos la Paz es una problemática que no solo concierne a la 
educación infantil sino a todas las personas, que tanto a adultos como a niños que necesitan la $\mathrm{Paz}$, que deben colocar cada uno un granito de arena para poder construirla. Sin embargo, reconocen que es importante fomentar el desarrollo integral de los niños, que es un trabajo que se debe hacer porque se va a enseñar a los niños los hábitos, los sentimientos, las costumbres, dado que traen cosas diferentes de sus comunidades y sus familias. Que es un trabajo arduo que deben hacer para cambiarles la mentalidad, los sentimientos, las actitudes y comportamientos, que en esta etapa de la educación infantil los niños tienen que llevar a un buen desarrollo, lo cual compete a todos los seres humanos. También, argumentan que allí se inicia el desarrollo de las habilidades socioafectivas, donde se le educa para el autocontrol, la disciplina y el inculcar valores como es el respeto, la tolerancia, el diálogo, qué son las que van a formar para la Paz. Educar para la Paz y la convivencia (Zurbano, 2001a, p. 3).

*Para los directivos es muy importante abordar la Paz desde la primera infancia, debido que en esta etapa es significativa la enseñanza de hábitos, que estimulen en el niño aprendizajes del comportamiento social, dado que esos hábitos no los tienen en sus familias, porque no los conocen o no les interesa, no tienen precisamente esos acompañamientos. Los niños llegan y no saben saludar, ni cepillarse, ni vestirse; por lo que las docentes de preescolar tienen un trabajo arduo, hay que enseñarles a que aprendan a convivir en Paz, en armonía, en comunicación con el otro. La propuesta de Educación Infantil para la Paz se centra en los niños y las niñas de 3 a 5 años de edad (Zurbano, 2001a).

*Para los directivos la Ley 1620 es una normatividad que se implementa en el manual de convivencia, para generar ambientes de relación y acuerdos entre toda la comunidad educativa, que la institución está organizada teniendo el decreto reglamentario, teniendo en cuenta los protocolos en cuanto a la tipificación de faltas, que ha sido socializado, con toda la comunidad educativa para que ellos sean conocedores de lo que tienen que cumplir. Está muy relacionada con las situaciones que se presentan el diario vivir, no solo en los entornos escolares sino en los entornos sociales y familiares, busca es apoyar a los diferentes actores de una comunidad educativa, para tener herramientas pedagógicas de cómo proceder ante estas. (Artículo 4, enciso 1, Ley 1620 de 2013).

*La Ley 1732 de 2014 de la cátedra de la Paz es considerada por los directivos docentes de obligatorio cumplimiento en las Instituciones Educativas, que busca generar ambientes más pacíficos desde el aula de clase, que hay que incluirla en los planes de estudio. Les parece que la propuesta es buena, dado que ha pasado el conflicto y se está en el posconflicto, dado que tiene mayor aplicabilidad saber que la Paz beneficia a todos y hace parte de los seres humanos de este querido territorio. (Artículo 6, Ley 1732 de 2014).

*Desde los contextos de interacción pedagógicos del preescolar, todas las docentes siempre responden de manera adecuada a las inquietudes de los niños y niñas, promoviendo de esta forma la internalización de la Paz, sin embargo, solo una utiliza palabras, frases y manifestaciones afectuosas como: "papito, mamita, mis amores", las demás no utilizan expresiones afectivas hacia los niños y las niñas. Para enseñar convivencia pacífica hay que transmitir convivencia pacífica (con nuestros pensamientos, palabras y obras). (Zurbano, 2001a, p. 12-13).

*En los nichos de interacción pedagógica en el nivel preescolar, los niños y niñas no realizan preguntas con relación a la $\mathrm{Paz}, \mathrm{ni}$ de los valores que esta conlleva, los niños y las niñas hablan de algunos valores que se 
consideran contribuyen a la Paz, pero solo en el momento de abordarlos, que son los establecidos en el currículo de la escuela. Dado que la Paz solo se aborda en el currículo como temática en el mes de septiembre, porque en Colombia se institucionalizó desde hace 26 años celebrar una semana por la Paz. Además, que en sus contextos de la familia y el barrio no se vivencia la Paz y los valores que la constituyen. Para enseñar convivencia pacífica hay que transmitir convivencia pacífica (con nuestros pensamientos, palabras y obras)" (Zurbano, 2001a, p. 13).

*Desde los contextos de interacción pedagógicos en el preescolar, todas las docentes siempre mostraron una actitud dinámica, pasiva y serena, esta disposición hacia estas actitudes contribuye a que los niños y las niñas puedan tener confianza y expresar con facilidad conocimientos y pensamientos que promueven la internalización de la Paz; no obstante la gran mayoría carece de manifestaciones verbales y gestuales afectivas hacia los niños y las niñas, que promueva que los niños y las niñas expresen más sus vivencias, sentimientos y emociones en el momento del trabajo de los valores propios de las competencias socioafectivas. Los aspectos afectivos y emocionales tienen una importancia especial en Educación Infantil. (Zurbano, 2001a, p. 67).

* La forma de comunicación en los contextos para el fortalecimiento de las competencias socioafectivas para la internalización de la Paz, entre los niños y las niñas con sus pares como con su maestra se caracteriza por ser horizontal, dado que los diálogos que se suscitan entre los agentes no evidencia jerarquización, es decir, no se distingue la voz entre las categorías estudiantes y de maestros. El código elaborado favorece posición individual del adquiriente" (Bernstein, 1994, p. 107). En el reconocimiento de la. (Bernstein, 1994, p. 36).

\section{SIGNIFICACIONES ACERCA DEL PROCESO DE INTERNALIZACIÓN DEL APRENDIZAJE POR LOS AGENTES EDUCATIVOS.}

*Para todos los docentes el proceso de internalización del aprendizaje se da por dos procesos: el interpsicológico desde el ámbito social y el intrapsicológico desde el ámbito individual. Que lo interpsicológico se refiere a la parte social, porque cada función mental superior del individuo primero es social, que es un proceso gradual y progresivo que se da a través de la interacción social que la persona toma del exterior; dado que los valores y costumbres se aprenden del medio social. $\mathrm{Y}$ el intrapsicológico lo que sucede al interior de cada niño, es mediante el dominio de sí mismo, del control y regulación de la persona, para aplicarlo en su cotidianidad, los aprendizajes son interiorizados por el ser humano y se convierten en parte de sus actitudes y comportamientos que luego exteriorizan a los demás. Que el desarrollo cultural del niño tiene en cuenta lo social y después lo individual. Internalizacion (Vigotsky, 1978, p. 94)..

*Para los docentes sí es importante, en el aula de clase, fortalecer las competencias socioafectivas para la internalización de la Paz en los niños y las niñas, educándolos emocionalmente para que sean adultos estables capaces de llevar buenas relaciones con todas las personas que los rodean. Para la formación de su autoimagen e integral, permitiendo desarrollar los valores y virtudes que conlleven a la Paz, preparándolos para afrontar y resolver conflictos en su cotidianidad por medio del diálogo evitando agresiones. La intervención educativa deberá buscar que el niño progrese en la identificación y manifestación sentimientos y emociones. (Zurbano, 2001a, p. 40).

*Los docentes argumentan que los espacios donde se fortalecen las competencias socioafectivas en los niños y niñas, en su mayoría son las salidas pedagógicas, el restaurante 
escolar y la familia que es necesario central, también, como primera entidad formadora de conductas, además, en el recibimiento y la salida de los niños y las niñas y que en cada espacio se genera una actividad de convivencia para la Paz. Potenciar las relaciones intercalases (Zurbano, 2001a, p. 17).

*Los docentes argumentan que los recursos didácticos más utilizados para promover la internalización de la Paz en los niños y las niñas se caracterizan por proyectos pedagógicos, que tengan que ver con la parte humana fundamentales para el fortalecimiento de valores, el árbol de la Paz. Las actividades rectoras como el cesto de los tesoros, el juego heurístico, los baja techos y actividades lúdicas que promuevan los valores a través de la música, las rondas, los títeres y por último las charlas sobre valores (respeto, tolerancia, compañerismo). La intervención educativa, manipular y respeto hacia los objetos. (Zurbano, 2001a, p. 47).

*Los docentes manifiestan que las estrategias más utilizadas en el aula de clase para promover internalización de la Paz son las actividades rectoras que se desarrollan diariamente en las que se enseñan los valores y se busca una buena convivencia, la asamblea y la caja de tesoros. Las salidas pedagógicas que es una estrategia que conlleva a compartir entre los estudiantes. Los proyectos pedagógicos como el árbol de la $\mathrm{Paz}$ que se evalúa diariamente con los niños que no cumplen su compromiso y se generan diálogos. "Cualquier actividad realizada puede ser útil para trabajar la dimensión relacional (Zurbano, 2001a, p. 143)..

*Los directivos docentes consideran que la internalización del aprendizaje, que es un proceso interdisciplinario, interpsicológico e intrapsicológico. Interdisciplinario porque es un proceso conjunto en todos los aspectos, interpsicológico, dado que se da a nivel social, de acuerdo al entorno social en el que se desenvuelve, es el desarrollo cultural del niño, de su ambiente, es el proceso mediante el cual un individuo incorpora dentro de sus patrones de personalidad una conducta prevaleciente en la sociedad. Que es intrapsicológico, porque se da al interior del niño, una actividad externa que se construye y comienza a suceder interiormente de forma personal y queda transformado en otro de carácter intrapersonal. La Internalización (Vigotsky, 1978, p. 94)..

*Los directivos docentes expusieron que los recursos didácticos que más utilizan los docentes de preescolar para internalizar la Paz son los juegos didácticos como: rompecabezas, fichas, láminas, loterías, juegos interactivos, canciones, sociodramas y también videos. Porque la enseñanza en el preescolar es muy lúdica, es muy importante porque es donde el niño empieza a socializarse, a aprender, a tener los hábitos. El dialogo, la comunicación, son los procesos que más se ve en las profesoras de preescolar, están con los niños enseñándoles a convivir en Paz a pesar de que vienen de un entorno bien complicado. $Y$ por último que utilizan la solución de problemas o dilemas. La intervención educativa, además de permitir a los niños manipular y respeto hacia los objetos $y$ materiales. (Zurbano, 2001a, p. 47).

*Los directivos docentes argumentan que los docentes de preescolar utilizan como estrategias pedagógicas para promover la internalización de la Paz los proyectos de aula en el que se desarrollan actividades como rondas, danzas, trabajos colaborativos, arte, que muestran los desempeños y las destrezas que adquirieron. Otras estrategias son las convivencias para promover un buen ser humano, la dramatización, el juego de roles, que descubre muchas de las problemáticas que se dan al interior del hogar y la exploración del medio que realizan los niños guiado por los docentes. Que todas estas estrategias conllevan al niño a una sana convivencia que puedan dentro de 
su rol desarrollar un trabajo colaborativo con el otro, de Paz en el aula de clase y esto puede que influir en todo el entorno escolar y en la casa. "Cualquier actividad realizada en la escuela infantil puede ser útil para trabajar la dimensión relacional (Zurbano, 2001a, p. 143).

*Los directivos docentes consideran que, mediante el fortalecimiento de las competencias socioafectivas, sí se puede promover la internalización de la Paz. Sobre todo con un buen trato, cuando alguien siente que otra persona le demuestra afecto, cariño y alegría. Buena comunicación y dialogo, ante la persona que se ve que comete una falta, hacerle caer en cuenta de sus errores, de cómo puede mejorar, para que haga un compromiso, se conoce el entorno del niño para que aprendan a vivir en Paz y armonía. Mediante una educación basada en valores, porque el desarrollo socioemocional y moral posibilita visto desde lo social, posibilita el desarrollo de los valores. Y en las asesorías, se les habla mucho de los valores cuando vienen con sus padres, ahí es donde se conoce la problemática que vive cada estudiante, es una historia diferente $\mathrm{y}$ desafortunadamente la mayoría de las historias son tristes. Las diferentes situaciones de comunicación para expresar (Zurbano, 2001a, p. 99).

*Los directivos docentes reconocieron como espacios en los que se trabajan las competencias socioafectivas en la institución las áreas físicas como: el polideportivo, la biblioteca, el auditorio, la sala audiovisual, laboratorios, el aula de clase, el patio, la sala de informática, punto vive digital, el auditorio y la sala de robótica, en cualquier lugar de la institución se les habla mucho de los valores. Y en espacios de tiempo como las buenas tardes, las direcciones de curso y orientaciones, que lo están haciendo a cada instante, porque todos los maestros quieren que los niños cambien de actitud, de forma de ser y su forma de vivir.
Potenciar las relaciones intercalases (Zurbano, 2001a, p. 17-20).

*Los recursos que utilizan los docentes en el aula de clase para promover las competencias socioafectivas para internalizar la Paz, algunas veces son canciones y cuentos y pocas veces son láminas y videos. Se evidencia que los recursos didácticos que utilizan son parte de algunas estrategias como el proyecto de guardianes del buen trato, donde se expone una lámina en la pared y puerta con el dibujo de dos osos. Los acuerdos de convivencia y pedagógicos donde se expone una lámina grande en la pared, con dibujos que muestran claramente sus acciones de estos Asambleas, donde las docentes leen los cuentos a los niños y las niñas y también, utilizan guías de acuerdo al valor del cuento que trabajan, para desarrollar diferentes actividades motrices finas. Nunca utilizan los otros recursos didácticos relacionados con los valores de los que se mencionan en el instrumento de investigación, dado que no cuentan con estos en la escuela, solo poseen algunos cuentos que son propiedad de las docentes y que no son adecuados a la etapa y a las características de desarrollo de los niños y las niñas del nivel preescolar, es decir, manejan unas reglas de secuencia explicitan enmarcadas en una pedagogía visible. Existen cuentos infantiles maravillosos, (Zurbano, 2001a, p. 147).Las reglas de secuencia pueden ser explicitas e implícitas. (Bernstein, 1994, p. 76).

*Los contenidos desde las competencias socioafectivas para la internalización de la Paz, son centrales y los desarrollan siempre tanto el docente como guía y el estudiante como adquiriente, contribuyendo a que se dé un proceso de intercambio de conocimientos, donde el docente siempre tiene en cuenta los conocimientos y casi siempre los pensamientos de los niños y las niñas, acerca del valor en el momento de la lectura de los cuentos, donde 
no se define ni se distinguen la voz entre las categorias docente estudiante. El principio de clasificación. (Bernstein, 1994, p. 37).

*Los docentes desarrollan los contenidos desde las competencias socioafectivas para la internalización de la Paz, mediante estrategias donde el estudiante siempre toma el roll de adquiriente, quiere decir que participa activamente del aprendizaje, solo en el momento de realización de las actividades desde los conocimientos. Algunas veces lo realizan mediante canciones alusivas a valores o hábitos. También, pocas veces mediante la literatura desde las asambleas con la lectura de los cuentos acerca de los valores que están estipulados en el plan de estudio por las dimensiones socioafectiva, ética y espiritual. Pocas veces realizan actividades con proyectos como los guardianes del buen trato, donde trabajan algunos valores que están estipulados en el plan de estudios. Muy pocas lo hacen por medio del planteamiento de preguntas, aunque en el modelo pedagógico constructivista de aprendizaje significativo se proyecta hacerlo, la mayoría de docentes no lo realizan. Nunca por proyectos de aula, dado que estos no se han implementado porque la mayoría de docentes desconocen la forma como se desarrollan. Las demás estrategias que se mencionan en el instrumento no se utilizan para trabajar los valores. El principio de enmarcación (Bernstein, 1994, p. 47). La práctica pedagógica. (Bernstein, 1994, p. 72-73).

*Los docentes brindan oportunidad para que los niños y niñas dialoguen sobre las competencias socioafectivas para internalizar la Paz. Siempre sobre conocimientos y casi siempre sobre pensamientos, en el momento de la lectura de los cuentos sobre los valores, los niños hablan de lo aprendido en la escuela, de esta forma se manejan códigos elaborados. Pocas veces sobre vivencias, sentimientos $y$ emociones que se generan en los niños y las niñas en el momento de la lectura de los cuentos, las docentes consideran que en estos espacios se comparten ayudan a construir las competencias socioafectivas solo desde el diálogo de conocimientos, se evidencia que manejan códigos restringidos. $Y$ algunas veces se dialoga en otros momentos y espacios sobre las vivencias desde la familia y el barrio que no son precisamente acerca de los valores, sino de las problemáticas, como la violencia física, verbal, la separación de los padres, el consumo de sustancias alucinógenas como el alcohol, la marihuana y otras, de los robos, atracos, las peleas entre la familia extendida y con vecinos. De que los padres, familiares y vecinos huyen y se esconden de las persecuciones por parte de grupos al margen de la ley y de las autoridades. Comentan hasta de las muertes que se suceden por ajustes de cuentas, entre grupos al margen de la ley, por robos, por violencia intrafamiliar, por deudas, etc., los niños y las niñas hablan de los sentimientos y emociones negativas que estos sucesos generan en ellos, nunca hablan de buenas acciones en sus contextos de interacción de la familia y el barrio. Los códigos restringidos más. Los códigos elaborados. (Bernstein, 1994, p. 101-116).

\section{CONCEPTUACIONES SOBRE LAS COMPETENCIAS SOCIOAFECTIVAS POR PARTE DE LOS AGENTES EDUCATIVOS.}

*Los docentes consideran que es la capacidad socioafectiva, para expresar sentimientos, emociones, opiniones, de manera adecuada para enfrentar dificultades con el dialogo. Son las emociones importantes en la formación y el desarrollo de la persona, evitando conflictos y aportando situaciones de Paz. Es el manejo de las emociones para poder enfrentar de forma conveniente cualquier situación que se puede presentar en la vida. Son los valores y actitudes, que ayudan a enfrentar o resolver de manera responsable conflictos en la vida cotidiana, estos se evidencian en 
los comportamientos en la relación cotidiana con su par, para la práctica de la convivencia. Competencias Socioafectivas. (MEN, 2010, p. 17) Educar para la Paz supone cultivar en los alumnos valores (Zurbano, 1998, p. 21).

*Los docentes consideran que las competencias socioafectivas son mediadoras de la internalización de la Paz, porque hay mediación de situaciones que llevan a contribuir a la Paz, ayudan a la toma de decisiones responsables, se aprende a tener buenas relaciones con el otro a no generar conflictos. Es interiorización, porque se vuelven parte de la cotidianidad de la persona, van a contribuir a que se evidencie en sus palabras, comportamientos y actitudes los valores de la Paz. Se promueve el desarrollo de la inteligencia emocional, permite mejores relaciones consigo mismos y con los demás. $Y$ porque que el contexto sociocultural influye en el niño. La Paz aglutina los valores fundamentales para la vida. (Zurbano, 1998, p. 23).

*Los docentes reconocen que dentro de sus aulas de clase promueven las competencias socioafectivas para internalizar la Paz, desde los valores con más frecuencia a partir de la tolerancia, la solidaridad, el respeto, la justicia, la esperanza, la bondad, la amistad, la alegría, el afecto y el dominio propio. Además, argumentan que trabajan otros valores como autoestima, gratitud, colaboración, humildad, sensibilidad, prudencia y honestidad. Que todos estos valores están fundamentados para aprender a convivir y ser generadores de Paz, que estructura el comportamiento de los niños y los niños. La Paz aglutina los valores fundamentales para la vida" (Zurbano, 1998, p. 23).

*Las docentes generan y mantienen el interés de los niños y las niñas en las competencias socioafectivas para internalizar la Paz. Primeramente desde acuerdos, que generan solución a conflictos, se exponen y se recuerdan todos los días, mediante el manejo de normas, de reglas. Con ambientes pacíficos de sana convivencia, haciendo que ellos se apoyen mutuamente, estableciendo vínculos afectivos, en el momento que se presenta un conflicto se dialoga con los niños, se buscan alternativas de solución y el pedirse disculpas cuando se lastiman. Cultivando los valores, se fomenta el respeto por el otro, desde los cuentos, motivándolo con actividades dinámicas mediadas por las actividades rectoras, juego, literatura, exploración del medio y el arte. Eso exige calma, dominio de la situación y aplicación de estrategias adecuadas. (Zurbano, 2001a, p. 92).

*Los docentes argumentan que los ambientes en los contextos de interacción pedagógicas, que propician en los niños y las niñas el fortalecimiento de las competencias socioafectivas para internalizar la $\mathrm{Paz}$, son principalmente el ser dinámico, en su orden le sigue el ser afectivo, luego sereno y por último pasivo. Las actitudes descritas hasta ahora tienen que generar un ambiente lleno de afectividad y ternura: (Zurbano, 2001a, p. 168).

*Los directivos conciben las competencias socioafectivas como actitudes que se deben desarrollar y se deben formar en el niño desde muy temprana edad. Son el reconocimiento de sentimientos de los propios y también, las de las personas que tienen alrededor. Son valores asociados con la formación integral de la persona. Son el saber hacer en el contexto, es decir es el conjunto de procesos cognitivos y conceptuales que un individuo pone a prueba en una aplicación y resolución determinada, para desempeñarse en un entorno. Lugar idóneo para que los alumnos aprendan las actitudes básicas de una convivencia. (Zurbano, 1998, p. 54).

*Los directivos docentes argumentan que las competencias socioafectivas son mediadoras de la internalización de la Paz, porque permiten el reconocimiento de los sentimientos de los docentes y hacen que los niños reconozcan los 
suyos. También, promueven el desarrollo ético ciudadano en la prevención de conductas de riesgo, mejora el ambiente y el clima escolar, para alcanzar la Paz y la buena convivencia. Además, fomentan el aumento de motivación al logro en el aprendizaje académico, el afecto es estímulo para su vida tiene un profundo valor en sí mismo, permitan a los niños y a los adolescentes desenvolverse, relacionarse mejor, tomar decisiones de acuerdo a sus valores. Bondad y cordialidad (Zurbano, 1998, p. 61).

*Los directivos docentes expresan que las competencias socioafectivas para internalizar la Paz se están trabajando a nivel institucional mediante los valores, donde se tienen establecidos unos principios y valores, más que todo los valores como el respeto, la tolerancia, el afecto, mencionan que en este me de septiembre en el proyecto de medio ambiente se trabaja actividades de autoestima y la Paz. Además, en el trabajo semanal, se enseña un valor y unas actividades por proyectos trasversales encargados de la disciplina, tanto en la jornada de la mañana como en la tarde desde los buenos días o buenas tardes y el maestro debe trabajarlo en el aula de clase durante la semana. $Y$ en proyectos de aula, se tienen dentro del Proyecto Educativo Institucional de forma transversal trabajar las competencias, dentro de ellas las socioafectivas, los valores, los principios, la relación, la interacción con los compañeritos, se les trabaja las normas, todo está dentro de los planes de aula, que además se hacen actividades como rondas, juego de convivencias, diálogos o reuniones con los padres de familia. Educar para la Paz supone cultivar en los alumnos valores (Transversales. Educación para la Paz, M.E.C., 1992, Zurbano, 1998, p. 21).

*Los directivos afirmaron que las
competencias socioafectivas se han
implementado a través de los principios

institucionales y los valores. Los principios institucionales que se encuentran estipulados en el Proyecto Educativo Institucional como la singularidad, permite reconocerse como ser único e irrepetible; la autonomía, es la capacidad de la persona para pensar, decidir, actuar por sí mismo y la convivencia, orientado a cuidar, proteger y desarrollar la vida en Paz. Que los valores que se trabajan dentro de los principios están respeto, amor, orden y honestidad. Responsabilidad y libertad. $\mathrm{Y}$ tolerancia, justicia, sinceridad, solidaridad y amor. Además, exponen otros valores como amistad, alegría, afecto, bondad, autoestima y autocuidado. La Paz aglutina los valores fundamentales para la vida. (Zurbano, 1998, p. 23).

*Para los directivos docentes, los docentes de preescolar generan el interés de los niños y niñas en las competencias socioafectivas para la internalización de la Paz. A través de la didáctica y la pedagogía para tener la atención de sus estudiantes, desde las estrategias y actividades que son dinámicas que les permite generar hábitos, para que los niños cambien las costumbres que traen de las casas, con los juegos, diálogos, cuentos que promueven el autodominio, la autoestima y la tolerancia. No tanto se les transmite conocimientos, sino que a través explorar el medio, ellos van conociendo, van mirando, van desempeñándose en el entorno. Del desarrollo de sentimientos y emociones, aprovechando el entusiasmo que ellos tengan en las actividades diarias para promover los valores, mediante el dialogo, el cariño que se les ofrece al estar pendientes de ellos, para la transformación de la inteligencia emocional. Suele decirse que el juego es el escaparate de la vida. Aprendiendo a jugar el niño aprende a convivir. (Zurbano, 2001a, p. 41).

*Los directivos docentes conciben que el ambiente que promueven los docentes de preescolar desde las competencias socioafectiva para internalizar la Paz se caracteriza por 
ser personas afectivas y dinámicas, todo el aprendizaje lo provocan en la lúdica para poder que los niños puedan sentirse bien. Se promueve y se trata con mucho amor a los estudiantes, se les da cariño, se evita que vaya a verlos alterados o violentos, de esto depende cómo se desempeñe en su vida escolar más adelante. En el manejo de las emociones, son personas muy serenas, muy calmadas, puesto que tienen que transmitir a los niños esos hábitos, desde el aula de clase lo propician para promover la internalización de la Paz. En la Educación para la convivencia pacífica es preciso trabajar los tres niveles propios de la educación en valores, (Zurbano, 2001a, p. 39).

*El docente siempre saluda, organiza e inicia su clase trabajando con un valor, nunca retoma la clase del día anterior respecto al valor trabajado, ni tiene en cuenta el estado de ánimo de los niños y las niñas ni pregunta el por qué. Los valores que se identificaron que más se trabajan son la amistad, solidaridad, el respeto, tolerancia, estos son los valores que están estipulados en el plan de estudios dentro de las dimensiones socioafectiva, ética y espiritual. Son los que las docentes consideran forman las competencias socioafectivas en los niños y las niñas, que contribuyen a generar un orden en los contextos de interacción pedagógicos de la escuela. Además, al iniciar la clase dentro de la actividad básica cotidiana trabajan los acuerdos pedagógicos, los compromisos de comportamiento, las normas del aula y pactos de amistad para la sana convivencia. Se evidencia que se implementa en el aula de clase prácticas pedagógicas enmarcadas tanto la pedagogía invisible como la visible. (Bernstein, 1994, p. 7273).

*Dentro de las competencias socioafectivas que trabajan los docentes para internalizar la Paz en el aula de clase, algunas se trabajan valores como la amistad y el respeto, pocas veces el valor de la solidaridad y muy pocas veces el valor de la tolerancia y las virtudes de la bondad, el afecto y la alegría y nunca trabajan las virtudes de la justicia, el dominio propio y la esperanza, todos estos valores y en más importancia las virtudes son necesarias para el desarrollo de las competencias socioafectivas de esta forma internalizar la Paz. Se evidencia que trabajan pocos valores para internalizar la $\mathrm{Paz}$, lo que genera unos códigos restringidos derivados de su contexto local, que predominan sobre los códigos elaborados del contexto universal de la escuela. Educar para la Paz es desarrollar todos aquellos valores que son necesarios para el desarrollo armónico de la personalidad. (Zurbano, 1998, p. 23). El código restringido no es favorable puesto que se toma una posición de receptor pasivo. El código elaborado favorece posición individual del adquiriente. (Bernstein, 1994, p.101-116).

*Todos los docentes del estudio siempre tienen en cuenta la participación de los niños y niñas, más que todo desde los conocimientos en el trabajo de los valores para promover las competencias socioafectivas para internalizar la Paz, de esta forma se generan diálogos de conocimientos y pensamientos acerca del cuento, canciones, láminas y videos, porque más que todo se suscitan en el momento del desarrollo de la clase en las estrategias y actividades mencionadas. En la forma de comunicación docente, adquiriente se muestra una enmarcación débil, pero se evidencia un enmarcamiento fuerte respecto a los conocimientos fundamentados en una pedagogía visible que pone énfasis en la trasmisión de los mismos. Cuando el enmarcamiento es fuerte, el transmisor regula de manera explícita las características distintivas del contexto comunicativo. (Bernstein, 1994, p. 47). La práctica pedagógica que se esté implementando permite determinar quién tiene el control. (Bernstein, 1994, p. 72- 73). 
*La práctica pedagógica de los docentes siempre se caracterizó dentro de los registros de observación por ser horizontal e invisible. Donde las relaciones que se suscitan son horizontales maestro orientador, facilitador de los procesos, no tradicionales, de acompañamiento se construyen los saberes en el momentos de la implementación de la estrategias y actividades en el espacio de interacción del aula. Los niños y las niñas son interlocutores válidos; en los espacios de discusión y es recíproca, donde se pretende llegar a un solo objetivo, que permitan la adquisición del conocimiento con el propósito de alcanzar las metas de aprendizaje respecto a los valores. Es invisible, porque el estudiante tiene el rol protagónico en el proceso de aprendizaje, para su formación desde el trabajo de los valores, la docente toma una actitud dinámica en cada clase que permite el manejo de un código elaborado en la relación con los niños y las niñas, donde no existen límites rígidos entre las categorías o agentes del proceso de formación. Se evidencia que se suscita una práctica pedagógica en la forma de comunicación invisible con una enmarcación débil, pero también una visible con una enmarcación fuerte, dado que el acto pedagógico pone énfasis los conocimientos y en su trasmisión. La práctica pedagógica que se esté implementando permite determinar quién tiene el control. (Bernstein, 1994, p. 72- 73).

*Los códigos que manejaban los docentes en el aula desde las competencias socioafectivas para internalizar la Paz. Desde los conocimientos y pensamientos siempre se definieron por ser códigos elaborados y desde las vivencias sentimientos y emociones siempre se caracterizaron por ser códigos restringidos. Los códigos elaborados de que suscitaron en el aula de clase desde la implementación de las estrategias y actividades alusivas al trabajo de los valores, la forma de comunicación no se distingue la voz entre las categorías docente y niños y niñas se enmarcaron en el diálogo e intercambio de saberes. Desde las vivencias, sentimientos y emociones fueron códigos restringidos dado que el aula es como el único espacio de aprendizaje, los contenidos fines en sí mismos, su naturaleza era academicista, enciclopédica y disciplinariedad asignaturista. Los códigos generaban la constatación cognitiva y mostró que las o demás dimensiones del ser no estaban presentes. El código restringido no es favorable puesto que se toma una posición de receptor pasivo. El código elaborado favorece posición individual del adquiriente. (Bernstein, 1994, p.101-116).

*La forma de comunicación y las actitudes de los niños y las niñas desde las competencias socioafectivas en los diferentes contextos de interacción del preescolar. Prevalece que la mayoría de ellos algunas veces demuestra ser bondadoso con sus compañeros, algunas veces demuestra tener dominio propio, en el momento de algún conflicto, algunas veces demuestran ser justos, cuando quieren tener algo, algunas veces demuestran tener esperanza en cuanto a lo que anhelan ser en el ahora y cuando crezcan, algunas veces demuestran afecto, hacia sus compañeros o docente y en la mayoría de contextos los niños y las niñas casi siempre demuestran alegría y en muy pocos contextos siempre están alegres dado que algunos ambientes los motivan. Se evidencian en los diferentes ambientes y espacios prevalecen códigos restringidos en la forma de comunicación de los niños y las niñas y dependencia del contexto local en cuanto a las actitudes y comportamientos que toman frente a las situaciones de conflicto que se presentan en la cotidianidad de la escuela. Dado que la mayoría de niños y niñas demuestran las vivencias de la familia y el barrio, se enojan con facilidad y agreden de forma verbal, física y con gestos a sus compañeros. Difícilmente comparten los materiales, los juguetes, los alimentos, argumentan que las madres les dicen que no compartan nada con sus compañeros. 
Su esperanza es ser como sus padres, familiares y vecinos, ser ladrón, indigente, guerrillero, paramilitar, pandillero, tener armas de fuego y armas blancas para pelear y matar; quieren consumir sustancias alucinógenas como marihuana y alcohol. Además, la mayoría de niños y niñas demuestran pocos gestos y palabras de afecto hacia sus compañeros $y$ docente. Se rescata que pocos niños y niñas denuestan actitudes y comportamientos enmarcados en los valores, quienes la mayoría de veces son víctimas de violencia por parte de sus compañeritos. Se videncia que el contexto local de la familia y el barrio, de los niños y las niñas prevalece sobre el contexto universal de la Escuela. El código restringido no es favorable puesto que se toma una posición de receptor pasivo. El código elaborado favorece posición individual del adquiriente. (Bernstein, 1994, p. 101-116).

*El ambiente físico y afectivo del aula no es muy motivador para el desarrollo de las competencias socioafectivas de los niños y las niñas. Dado que en la mayoría de ellos siempre se mueven, pelean, agreden, se inquietan, casi siempre interrumpen, conversan y gritan. Pocas veces duermen, silban, muy pocas veces son serenos y cantan y nunca son tranquilos $y$ pasivos. Esto genera dificultad en el desarrollo las habilidades cognitivas superiores como la concentración y la atención. Solo algunos niños y niñas se muestran motivados y son los que participan activamente en el desarrollo de las estrategias y actividades acerca de los valores y expresan sus conocimientos y pensamientos durante el desarrollo de la clase. Las actividades son de un tiempo prolongado y no están acorde con el tiempo de atención y las etapas y características de desarrollo que poseen los niños en el preescolar. Se evidencia que en la práctica pedagógica se generan unas reglas de secuencia explicitas e implícitas. Reglas de Secuencia explicitas e implícitas (Bernstein, 1994, p.75 y 76).

\section{CONCLUSIONES}

\section{Conclusiones sobre los hallazgos relacionados con la Paz.}

*La gran mayoría de agentes educativos manejan un código restringido frente al concepto de Paz, negativa y positiva solo muy pocos agentes reconocen la $\mathrm{Paz}$ como un estado interior y que es imperfecta. (López, 2001).

*Todos los agentes educativos consideran que la Paz es una problemática que se presenta desde la educación infantil, dado que los niños y las niñas se encuentran inmersos en contextos locales del barrio y la familia, donde vivencian que los conflictos son solucionados por medio de la violencia. (Zurbano, 2001a).

*Los agentes manejan un código restringido en cuanto al concepto que tienen con relación a las normas del Ministerio de Educación Nacional, para la prevención de la violencia y promoción de la Paz. (Ley 1620 de 2013).

${ }^{*}$ Respecto a la Cátedra de la Paz, no es coherente la respuesta de los agentes educativos con los referentes estipulados en el PEI y practica pedagógica, dado que aseguran que ya está trasversalizada en el currículo; pero la realidad evidencia que no se ha implementado. ( Ley 1732 de 2014).

*Se suscita unas formas de comunicación visibles-verticales con una enmarcación fuerte entre los docentes y los estudiantes, dado que el acto pedagógico pone énfasis en la trasmisión de los conocimientos. (Bernstein, 1994). ${ }^{*} Y$ una forma de comunicación invisiblehorizontal con una enmarcación débil con sus pares, en otros espacios comparten sus vivencias, sentimientos y emociones. (Bernstein, 1994). 


\section{Conclusiones sobre los descubrimientos en referencia a la internalización del proceso de aprendizaje.}

*Todos los agentes educativos manejan un código elaborado frente al concepto de internalización, como dos procesos el interpsicológico e intrapsicológico y con una relación pedagógica y viceversa. (Vigotsky, 1978).

*Los espacios físicos legítimos que promueven las competencias socioafectivas para internalizar la $\mathrm{Paz}$, son solo los que posee la institución, el aula de clase y la ludoteca. (Zurbano, 2001b).

*La institución educativa carece de recursos didácticos adecuados a la etapa del desarrollo de los niños y las niñas de este nivel, los pocos que utilizan son de propiedad de las docentes. (Zurbano, 2001b).

*No hay coherencia entre lo que los docentes argumentan, acerca de la implementación de todas las actividades rectoras con lo evidenciado en los registros de observación la única actividad rectora es la literatura, actividades aisladas y proyectos sin continuidad ni trasversales en el currículo. (Zurbano, 2001b).

*El ambiente físico y afectivo del aula no es muy motivador el desarrollo de las estrategias pedagógicas no son pertinentes, ni coherentes con el tiempo de atención que poseen en este nivel, trabajan pocos y los mismos valores y desarrollan pocas habilidades de pensamiento superiores. (Bernstein 1994).

\section{Conclusiones de lo encontrado desde las competencias socioafectivas.}

*Los agentes educativos manejan un código elaborado frente al concepto de competencias socioafectivas, lo relacionan con la expresión de sentimientos y emociones en la dimensión individual y social, mediado por los valores; aunque no tienen en cuenta las virtudes de la Paz. (Transversales. Educación para la Paz, M.E.C., 1992, Zurbano, 1998).

*No hay coherencia con lo que los agentes educativos argumentan frente a la promoción de las competencias socioafectivas, desde los valores, con lo arrojado en los registros de observación; argumentan que trabajan todos los valores y virtudes de la Paz, pero la realidad es que trabajan pocos valores y es imperceptible el trabajo de las virtudes de las Paz. (Transversales. Educación para la Paz, M.E.C., 1992, Zurbano, 1998).

*La forma de organización de los niños, las niñas y la docente en el aula, expresa una concepción tradicional y jerárquica del proceso de formación. (Bernstein, 1994).

${ }^{*}$ El fomento de las competencias socioafectivas, se abordan desde una pedagogía visible, donde los conocimientos priman sobre los procedimientos y actitudes, que conceptualicen el valor; mas no se trabaja con experiencias. (Chaux 2012) y (Bernstein, 1994).

*La naturaleza de la práctica pedagógica, se caracteriza por ser vertical se diferencia rol de cada uno de ellos, manejan unos códigos restringidos; no se promueve que los niños y las niñas hablen de vivencias, sentimientos $y$ emociones en la familia y el barrio. (Bernstein, 1994).

*El capital simbólico de los niños y las niñas frente al fomento de las competencias socioafectivas para la internalización de la Paz, tiene una relación directa con su base material de valores antiéticos y dependencia de su nicho local, la familia y el barrio. (Martín, 2004).

*Es imperceptible el trabajo de las virtudes de la Paz, lo que generan unos códigos restringidos derivados de su contexto local de 
valores antiéticos, que predominan sobre los códigos elaborados del contexto universal de valores. (Bernstein, 1994).

\section{RECOMENDACIONES}

\section{Recomendaciones relacionadas sobre la paz.}

*Empoderar teórica y conceptualmente a los agentes educativos en los postulados de este estudio referente al concepto de Paz, es decir manejar un código elaborado, para lograr trasformación del estilo de vida desde su interior hacia sus semejantes, como plantea en la Tesis de la Paz Interior y la Teoría de la Paz Imperfecta. (Muñoz, 2001, p. 38).

*Implementar de forma trasversal en el currículo la Cátedra de la Paz y sus contenidos, desde los conocimientos, procedimientos y actitudes, como se estipula las directrices del Ministerio de Educación Nacional y el referente legal de este estudio. Ley 1732 de 2014.

${ }^{*}$ Que las docentes promuevan formas de comunicación más invisibles-horizontales con una enmarcación débil con los niños y las niñas, donde el acto pedagógico referente a la internalización de las virtudes de la Paz, desde la pedagogía invisible (Bernstein, 1994).

\section{Recomendaciones en referencia a la internalización.}

${ }^{*}$ Que la institución educativa promueva otros espacios físicos fuera de la escuela, donde los niños y las niñas interactúen con la comunidad, lleven a la práctica las virtudes para internalizar la Paz desde las competencias socioafectivas, coherente con los planteamientos teóricos de (Zurbano, 2001a).

${ }^{*}$ Que la institución educativa implemente recursos didácticos variados y pertinentes, entre ellos cuentos apropiados para la etapa del desarrollo de los niños y las niñas de este nivel, además, que las docentes los manejen de forma significativa y motivadora. (Zurbano, 2001b).

3. Las docentes deben promover una formación menos jerarquizada con identidades menos diferenciadas entre ellas, los niños y las niñas, donde utilicen más estrategias enmarcadas en todas las actividades rectoras, que los motiven a participar, disfrutar y a aprender (Bernstein, 1994).

*Los docentes deben promover ambientes físicos y afectivos adecuados, tener en cuenta las reglas de secuencia, es decir; las etapas de evolutivas desarrollo y las características que se presentan los niños y las niñas en cada una de ellas, con estrategias motivadoras que capten su atención. (Bernstein, 1994).

*Fortalecer las prácticas pedagógicas universales sobre las virtudes para internalizar la Paz y sus valores en la escuela; para que predominen sobre las prácticas locales de valores antiéticos de la familia y el barrio, de los niños y las niñas. (Bernstein, 1994).

\section{Recomendaciones desde las competencias socioafectivas.}

*Desde la Teoría de la Transmisión Cultural, es importante implementar la pedagogía invisible que el proceso de formación este centrado en el estudiante, para que desarrolle los conocimientos, pensamientos, sentimientos y emociones, que generen comportamientos y actitudes hacia las virtudes para la internalización de la Paz, de esta forma dar solución a la problemática de la violencia (Bernstein, 1994).

*Trabajar desde un currículo experiencial los contenidos conceptuales, procedimentales y actitudinales, para internalizar las virtudes de la Paz, desde las competencias socioafectivas donde los niños y las niñas experimenten $y$ expresen sus sentimientos, emociones y pensamientos con los miembros de su comunidad, actividades pedagógicas con obras humanitarias (Chaux, 2012) y (Zurbano, 2001a). 
*Las docentes deben fomentar contextos más universales, que promuevan la internalización de las virtudes de la Paz desde las competencias socioafectivas, que tengan dominancia sobre el contexto local de valores antiéticos que viven los niños y las niñas, de esta forma; lograr que queden situados como sujetos pedagógicos competentes en lo socioafectivo (Bernstein, 1994).

*Se ha de promover una práctica pedagógica en la forma de comunicación entre las docentes, los niños y las niñas, que se caracterice por ser horizontal y se manejen unos códigos elaborados. Que dialoguen sobre sus vivencias, sentimientos y emociones que generan las experiencias cotidianas. (Bernstein, 1994).

\section{REFERENCIAS BIBLIOGRÁFICAS}

Agüero, E. C. (2015). Desafíos de la educación para la Paz hacia la construcción de una cultura de Paz. Revista Electrónica Educare, 19(2), 135-154.

Álvarez, A C \& Álvarez, V (2014). Métodos en la investigación educativa. México D. F.: Universidad Pedagógica Nacional. Recuperado de: https://www. gestiopolis.com/la-elaboracion-deldiseno-metodologico-reto-importante-la

Álvarez, F. (1994). Estadística Aplicada: Fundamentos teóricos y ejemplos comentados. Cádiz, España: MIGNON Libreros.

Ávila, M. \& Paredes, Í. (2010). Educar para la Paz desde la educación inicial. Omnia, 16(1), 159-179.

Bernstein, B. (1994). La estructura del discurso pedagógico: Clases, códigos y control. (2 a Ed.). Madrid: Morata.
Briones, G. (1998a). La investigación en el aula y en la escuela. Bogotá: Editorial Gente Nueva.

Caireta, M., \& Barbeito, C. (2005). Introducción de conceptos: Paz, violencia, conflicto. Seminario de Educación para la PazAPDH. Educar para la Paz. Una propuesta posible. Catarata. Madrid: Programa de Educación para la Paz.

Castañeda, M, Cabrera, A \& Navarro, Y. (2010). Procesamiento de datos y análisis estadísticos utilizando SPSS: Un libro práctico para investigadores y administradores educativos. Porto Alegre- Brasil: Pontificia Universidad Católica de Rio Grande do Sul. EDIPUCRS. Recuperado de http://www. pucrs.br/edipucrs/spss.pdf.

Chaux, E. (2012). Educación, convivencia y agresión escolar. Bogotá: Aguilar.

Galino, M. (2012). Educación por competencias.

Recuperado de: http://www.esc. geologia.efn.uncor.edu/wpcontent/ uploads/2013/05/competenciasmonicagalino-2012.pdf.

Galtung, J. (1985). Sobre la Paz. Barcelona: Fontamara.

Galtung, J. (2003). Violencia cultural. Documento Nro. 14. Edita: Gernika Gogoratuz. Centro de Investigación por la Paz. Fundación Gernika Gogoratuz. Recuperado de https://www. gernikagogoratuz.org/web/uploads/doc umentos/202892edd66aafe5c03dacf12 98fd7f8938fae76.pdf.

Hernández, R., Fernández-Collado, C., \& Baptista, P. (2006). Metodología de la Investigación. (4a Ed.). México: McGraw-Hill. 
Hurtado de Barrera, J. (2002). El proyecto de investigación. Bogotá D.C.: Cooperativa Editorial. Magisterio.

López, M. H. (2011). Teorías para la Paz y perspectivas ambientales del desarrollo como diálogos de imperfectos. Revista Luna Azul, 33.

Martínez, V. (2001). Filosofía para hacer las paces. Barcelona, España.

Meneses, C. (2019). Apuntes para trabajar con NVIVO 12 PLUS. Madrid: Universidad Pontificia Comillas. Recuperado de https://riuma.uma.es/xmlui/ handle/10630/17598.

Ministerio de Educación Nacional. (2010). Aprender a jugar: Instrumento diagnóstico de competencias básicas en transición. Documento No. 13. Bogotá.

Molina, B., \& Muñoz, F. A. (2004). Manual de Paz y conflictos. Granada: Editores Universidad de Granada. Recuperado de https://dialnet.unirioja.es/servlet/ libro?codigo $=6645$.

Muñoz, F. A. (2004). Manual de Paz y conflictos. Recuperado de: Romero-Saldaña, M. (2016). Metodología de la investigación. Pruebas de bondad de ajuste a una distribución normal. Revista Enfermería del Trabajo, 6(3), 105-114. http://www. ugr.es/ eirene/publicaciones/eirene manual.html.

Tortoza, S. et al. (2012). Desarrollo de los procesos cognoscitivo: Teoría de Vigotsky. En L. S. Vigotsky (1978), Pensamiento y lenguaje. Madrid. España: Paidós. Recuperado de conocermasinvestigando.blogspot. com/2012/02/teoria-de-vigostky.html.
Vander Zanden, J. W., \& Wolfson, L. (1990). Manual de psicología social. Paidós.

Vigotsky, L. S. (1978). El desarrollo de los procesos psicológicos superiores. Barcelona: Crítica. Recuperado de http://www.terras.edu.ar/biblioteca/6/ TA_Vygotzky_Unidad_1.pdf

Zurbano, J. L. (1998). Bases de una educación para la Paz y la convivencia. Gobierno de Navarra. Departamento de Educación y Cultura. Pamplona, España: Gráficas Ona. Recuperado de: https://es.scribd. com/document/325848559/ZurbanoBases-de-Una-Educacion-Para-LaPaz-y-La-Convivencia.

Zurbano, J. L. (2001a). Educación para la convivencia y para la Paz: Educación infantil. Pamplona, España: Gobierno de Navarra. Departamento de Educación y Cultura. Recuperado de http://dpto. educacion.navarra.es/publicaciones/ pdf/conv_pri.pdf.

Zurbano, J. L. (2001b). Educación para la convivencia y para la Paz: Educación Primaria. Pamplona, España: Gobierno de Navarra. Departamento de Educación y Cultura. Recuperado de http://dpto. educacion.navarra.es/publicaciones/ pdf/conv_pri.pdf. 